\title{
THE LABOR MARKET IN THE CONTEXT OF GLOBALIZATION
}

\author{
M. Shemyakina ${ }^{1}$, E. Murzina ${ }^{2}$, A. Burkov ${ }^{3}$
}

\section{Abstract}

The article provides an analysis of indicators that can help assess the safety of the national labor market and its involvement in globalization processes. Approbation of the results was carried out on the basis of the analysis of the labor market in Russia.

Keywords: labor market, international labor migration, globalizationIntroduction.

doi: http:doi.org/10.15350/UK_3/5/2

Современный этап развития отношений во многих сферах определяется таким понятием как глобализация, которое в свою очередь характеризуется увеличением масштабов экономических процессов международного обмена (трансграничных потоков капитала, товаров, услуг, информации, пространственную и институциональную интеграцию рынков), возрастающим воздействием на структурные характеристики национальных и региональных экономик и эволюцию и трансформацию социально-экономических систем и институтов.

M. Кастельс (Kastels, 1996) считал, что глобализация экономики обусловлена созданием глобальной информационной сети, которая представляет материальную основу новой экономической системы глобальной. Эта новая экономика способная работать как единая система в режиме реального времени в масштабе всей планеты. Как мы считаем, к процессу исследования рынка труда, и, в частности, одного из его главных показателей «миграции рабочей силы», данное положение также применимо, т.к. миграция рабочей силы выступает условием глобализации рыночного пространства. Впервые попытки анализа миграции рабочей силы- вопросы взаимной адаптации населения и капитала в границах определенной территории поднимаются в работах Д. Рикардо (Ricardo, 1852) и А. Маршалла (Marshall ,1892).

Существует две точки зрения о влиянии глобализации на рынок труда. С одной стороны, интеграция приводит к процветанию и развитию, особенно для стран с переходной экономикой. В первую очередь, это связывается с ростом производительности и экономическим ростом. С другой стороны, экономическая интеграция может привести к увеличению неравенства в промышленно развитых странах, или увеличить безработицу, если трудовым законодательством предусмотрена

\footnotetext{
${ }_{1}^{1}$ Marina Shemyakina, Candidate of Science, Associate Professor, Volga State University of Technology, Russia.

2Elena Murzina, Candidate of Science, Associate Professor, Volga State University of Technology, Russia.

${ }^{3}$ Aleksey Burkov, Doctor of Economics, Professor, Mari State University, Russia.
} 
корректировка в сторону понижения заработной платы неквалифицированных рабочих. (Wood 1994).

В докладе ОЭСР (OECD, 2007) обосновывается необходимость изучения рынков труда стран- членов БРИК, т.к. их совокупный ВВП составляет четверть от мирового. В данной статье нами рассматривается один из национальных рынков труда страны- участницы БРИКС - Российской Федерации и предпринимается попытка его анализа в рамках вопроса влияния глобализационных процессов на него.

Вовлеченность национального рынка труда в глобализационные процессы и его безопасность определяется, на наш взгляд, на основе выделенных групп индикаторов. Первую группу составляют показатели, на основе которых производится оценка национальной безопасности рынка труда. К ним отнесены: доля занятых лиц в общей численности населения в возрасте 15 - 72; уровень безработицы; доля неформального сектора в общей занятости; работающие бедные; доля занятых с чрезмерной продолжительностью рабочих часов; доля занятых с низким уровнем заработной платы; сегрегация в видах занятий (профессий) по половому признаку; гендерный разрыв в заработной плате; производительность труда (темпы роста); неравенство в распределении доходов; темпы инфляции; доля заработной платы в ВВП. Анализ перечисленных индикаторов позволяет идентифицировать угрозы безопасности национального рынка труда и определить мероприятия по их снижению. Вторую группу индикаторов составляют показатели, анализ которых позволяет определить влияние глобализационных процессов на национальный рынок труда и идентифицировать угрозы его безопасности. Основу данной группы составляют показатели, характеризующие миграцию и ее структуру. При этом под безопасностью национального рынка труда в исследовании понимается такое состояние рынка труда, при котором обеспечиваются защита национальных интересов, устойчивость к внутренним и внешним угрозам, способность к развитию.

Индикаторы для определения уровня национальной безопасности рынка труда в условиях глобализации

В исследовании проведен анализ выделенных нами индикаторов для определения уровня национальной безопасности рынка труда в условиях глобализации.

Значение показателя доля занятых лиц в общей численности населения в возрасте 15 - 72 (Fig. 1.) как всего, так и в разрезе структурных элементов, свидетельствует о стабильности экономической занятости и составляет в среднем около $65 \%$. 


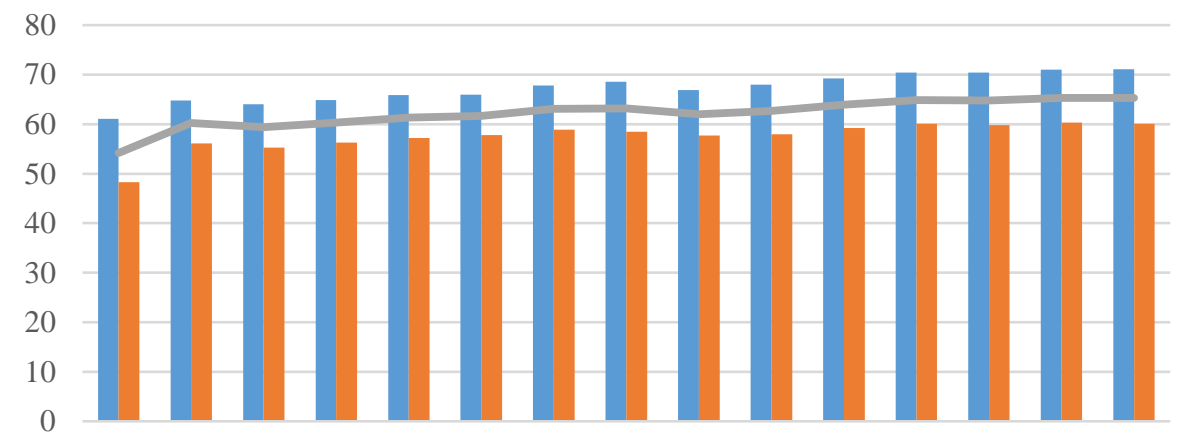

200120022003200420052006200720082009201020112012201320142015

Мужчины — Женщины $\longrightarrow$ Всего

Fig. 1. Доля занятых лиц в общей численности населения в возрасте $15-72$, \%

Анализ уровня безработицы (Fig. 2.) свидетельствует о снижении значения данного показателя, что на наш взгляд связано с эффективной государственной политикой, в частности с применением таких мер как: (a) содействие распространению информации; (b) переобучение; (c) содействие росту мобильности населения; (d) содействие самозанятости. При этом следует отметить, что в 2015 г. В России создана своеобразная «подушка» безопасности (количество вакансий на рынке труда превышает число безработных).

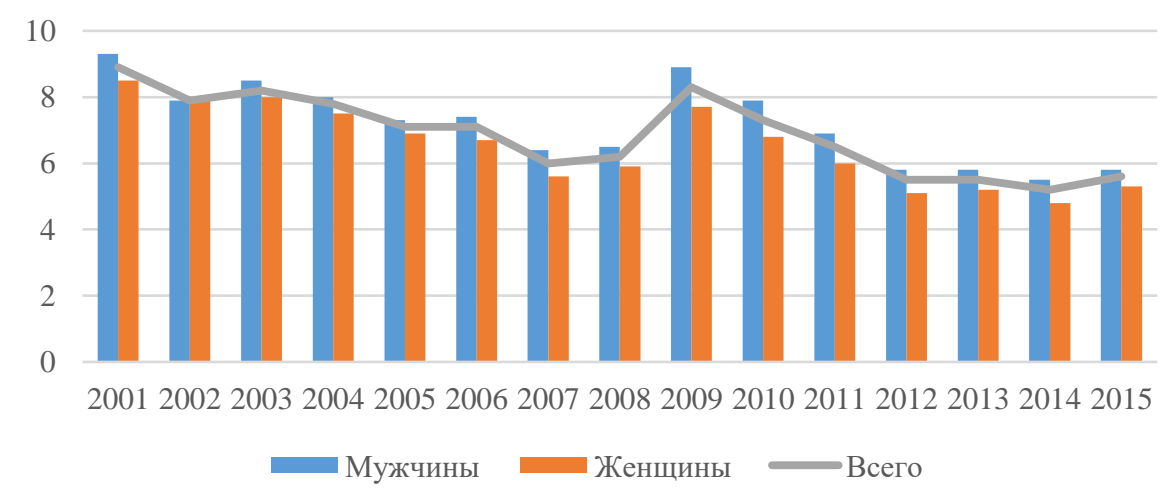

Fig. 2. Уровень безработицы

Одним из негативных индикаторов на рынке труда выступает рост доли неформального сектора в общей занятости (Fig. 3.). В первую очередь мы связываем такой рост с высокой налоговой нагрузкой. На наш взгляд, данный показатель может быть занижен, в связи со сложностью его определения. 


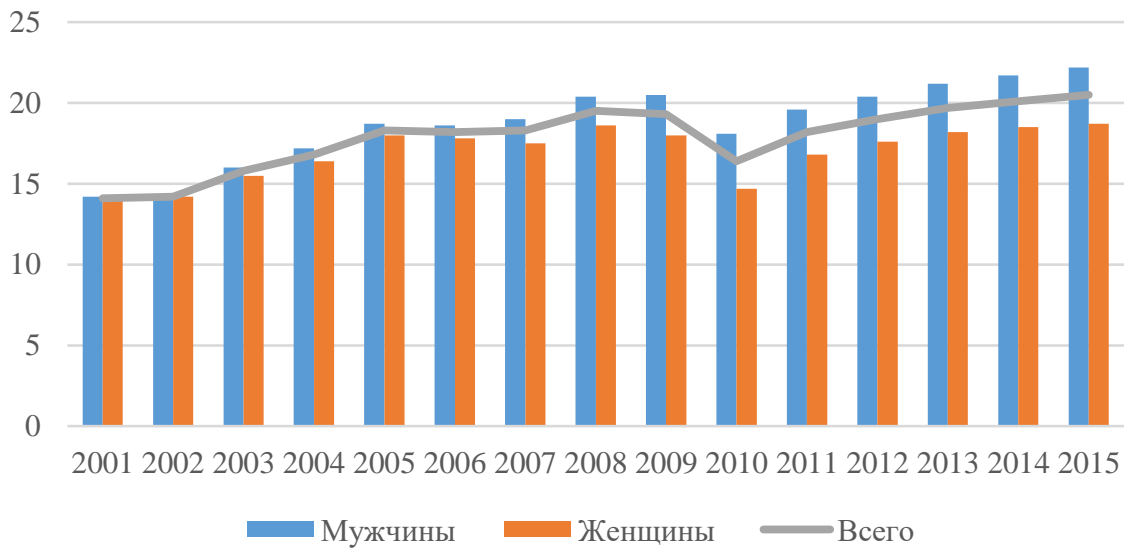

Fig. 3. Доля неформального сектора в общей занятости, \%

Положительная динамика наблюдается по показателю работающие бедные (Fig. 4.). Несмотря на небольшой рост в 2016 г. по сравнению с 2014 г. следует отметить снижение данного показателя за последнее десятилетие.

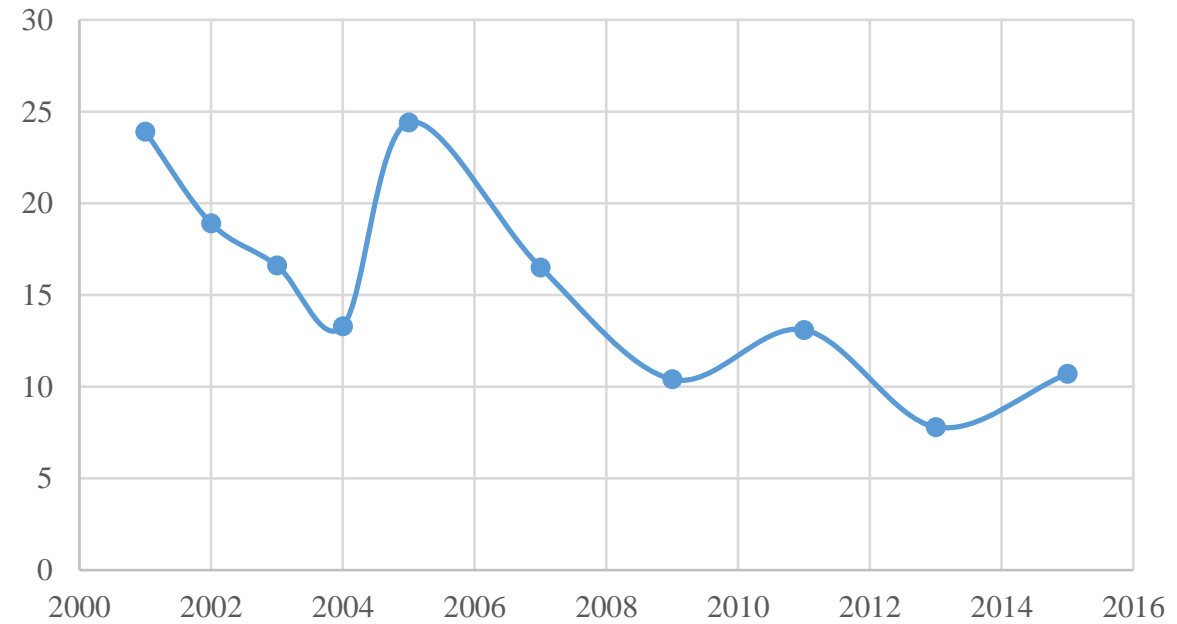

Fig. 4. Работающие бедные

В абсолютном отношении доля занятых с чрезмерной продолжительностью рабочих часов снижается (Fig. 5.). Данная тенденция является общемировой и в первую очередь связана со снижением экономических показателей и, как следствие, сокращением рабочих часов. 


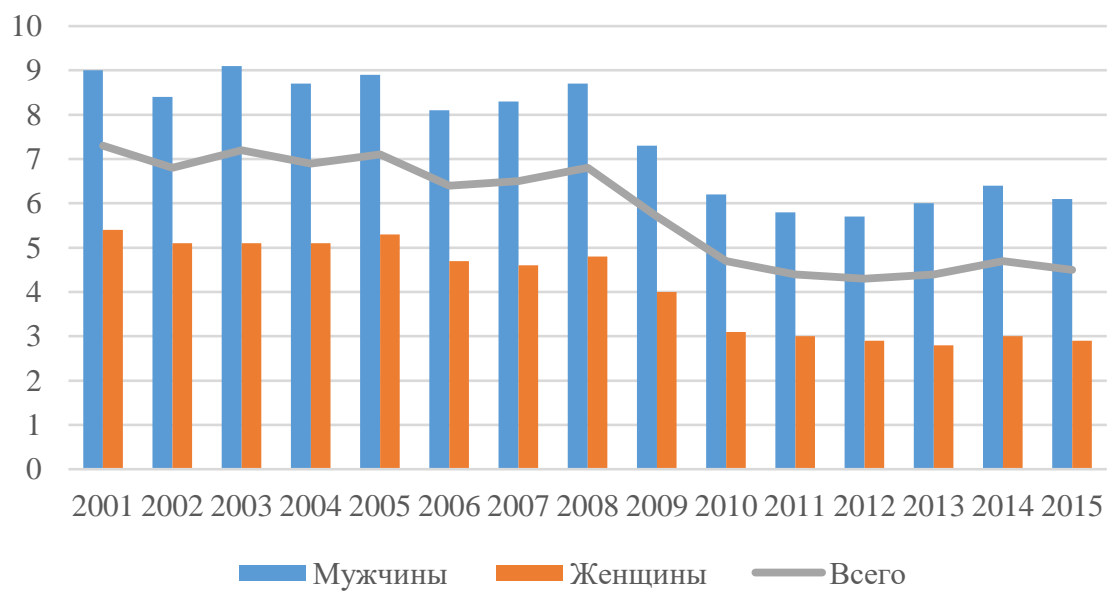

Fig. 5. Доля занятых с чрезмерной продолжительностью рабочих часов

(более 48 часов в неделю; «фактическое» количество часов), \%

Доля занятых с низким уровнем заработной платы незначительно (менее 1 процентного пункта) снизилась (Fig. 6.). Однако, данный показатель 27,3 \% остается достаточно высоким, т.к. он показывает, что треть работающих получает оплату труда ниже прожиточного минимума. При этом наблюдается явный гендерный разрыв: количество женщин на $13 \%$ превышает мужчин.

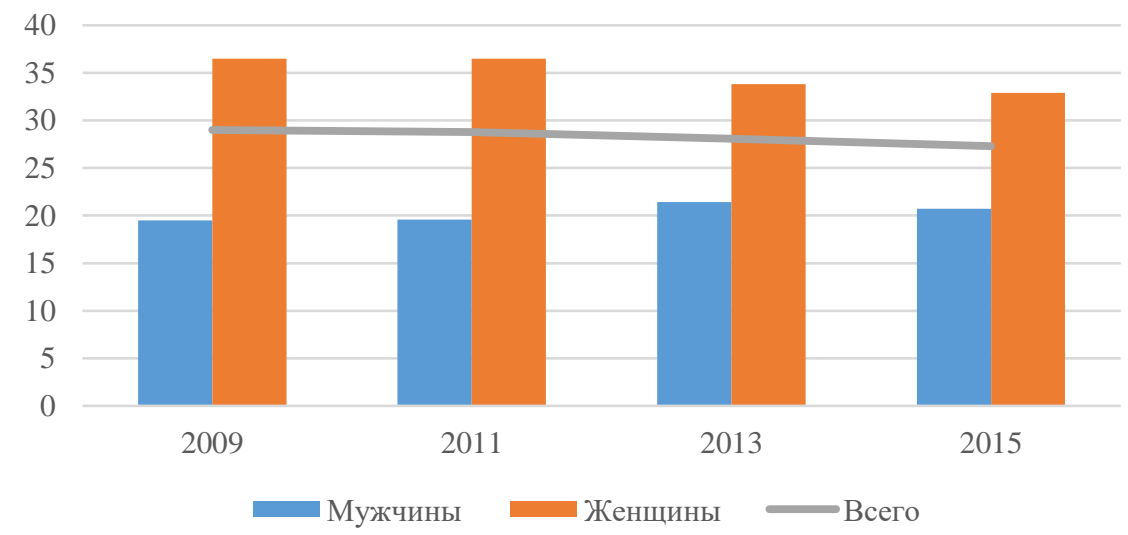

Fig. 6. Доля занятых с низким уровнем заработной платы (ниже 2/3 медианы почасового заработка), \% 
Сегрегация профессий по половому признаку сохраняется (Fig. 7) примерно на том же уровне, что и в последние 10 лет. В основном такая тенденция характерна для руководящей группы должностей.

Соглашаясь с Концепцией государственной миграционной политики Российской Федерации на период до 2025 года, следует отметить, что одной из стратегических задач является создание условий и механизмов для привлечения востребованных экономикой высококвалифицированных и квалифицированных специалистов разного профиля, предпринимателей и инвесторов на долгосрочной основе.

\section{References}

[1] Кастельс М. Информационная эпоха: экономика, общество и культура / Пер. с англ. под науч. ред. О. И. Шкаратана. М.: ГУ ВШЭ, 2000. 608 с

[2] Рикардо Д. Начала политической экономии и налогового обложения. Избранное/Д. Рикардо; [пер. с англ; предисл. П.Н. Клюкина]. М.: Эксмо. 2008. 960 с. с.168

[3] Альфред М. Основы экономической науки/В.И. Бомкин (пер. с англ.) Дж. М. Кейнс (предисл.) //М.: Эксмо. 2007. С. 265-310

[4] The Effects of Globalisation on Labour Markets,. Productivity and Inflation. Nigel Pain, Isabell Koske. OECD

[5] Концепция государственной миграционной политики Российской Федерации на период до 2025 года 